\title{
Influence of Drought Stress on Cytological Behavior of Green Manure Crop Sesbania cannabina Poir.
}

\author{
Nitisha Srivastava* ${ }^{\dagger}$ and Girjesh Kumar \\ Plant Genetics Laboratory, Department of Botany, University of Allahabad, \\ Allahabad-211002, Uttar Pradesh, India
}

Received January 7, 2014; accepted May 1, 2014

\begin{abstract}
Summary Among the most important environmental stresses, drought is the most significant stress affecting crop production. Effects of drought stress on the morphological parameters of plants are well studied and understood, but studies on the effect of drought stress on the chromosomal biology of plants are scarce. Therefore, the present study was conducted to study the effect of drought stress on the chromosomal biology of the drought-resistant green manure crop Sesbania cannabina. The present experimentation was conducted at the Department of Botany, University of Allahabad. Dry and healthy seeds of Sesbania cannabina variety ND-1 were soaked in distilled water and used for sowing in experimental pots to raise the population. After 15 days, seedlings were exposed to drought stress for different time durations (viz., 10, 15 and 20 days). On the onset of budding, young floral buds were fixed in carnoy's fixative and were used for cytological studies. Cytological studies clearly showed the chromotoxic behaviour of drought stress.
\end{abstract}

Key words Chromosomal biology, Chromotoxicity, Drought resistance, Pollen fertility.

Drought, whenever and wherever it occurs, causes potential damage to crops. Lack of soil moisture restricts plant growth, both in terms of the total quantity of tissue produced and the time that the plant tissue is produced. In a drought the plant has to rely on the stored reserves for a longer period of time, thus reducing stored nutrients for future use and increasing the plant's susceptibility to damage in extended periods of drought and grazing uses. The lack of available moisture usually reduces the length of the growing season.

A crucial aspect in all the studies dedicated to drought tolerance is the assessment of the degree of drought tolerance of different genotypes. In many studies, the identification of tolerant and susceptible cultivars is based on few physiological measures related to drought response (Cattivelli et al. 2002). The difficulty in identifying a physiological parameter as a reliable indicator of yield in dry conditions has suggested that yield performance over a range of environments should be used as the main indicator for drought tolerance (Voltas et al. 2005). Furthermore, a number of regression techniques of yield against environmental indices as independent variables were developed to evaluate genotype adaptability. Several indices were proposed to describe yield performance of a given genotype under stress and non-stress conditions or in comparison with the average yield or the yield of a superior genotype (Finlay and Wilkinson 1963, Eberhart and Russell 1966, Fischer and Maurer 1978). A physiological approach would be the most attractive way to develop new varieties (Araus et al. 2008), but breeding for specific, sub-optimal environments involves a deeper understanding of the yield-determining process. In worst case scenarios, the plants completely die. Certain plants have devised mechanisms to survive under low water

\footnotetext{
* Corresponding author, e-mail: srivastava_nitisha@yahoo.com

${ }^{\dagger}$ Present address: Botanical Survey of India, Hqrs., C.G.O. Complex, 3rd MSO Building, 5th Floor, DF Block, Sector-I, Salt Lake City, Kolkata-700064, West Bengal, India

DOI: $10.1508 /$ cytologia. 79.325
} 
conditions. These mechanisms have been classified as tolerance, avoidance or escape (Kramer and Boyer 1995). To survive drought stress, a plant must either extract more water from the soil and/or effectively control the amount of water it loses through transpiration. The efficiency of soil water uptake by the root system as well as control of stomatal aperture are key factors in determining the rate of transpiration. The root characteristics including rooting depth, thickness of roots and root length density that determine water uptake during drought (Cruz et al. 1992) may be influenced by the assimilate partitioning pattern. Sesbania is characterized by an ability to tolerate and survive under conditions of drought and waterlogging. With respect to the cytological aspect, the present study focuses on stress by drought on Sesbania pea. There are many studies on the impact of drought on plant growth, but less work has been done on the cytogenetical behaviour of plants due to drought stress. Therefore, the main aim of the present study was to investigate the effects of drought stress on the chromosomal biology of Sesbania pea.

Materials and methods

\section{Field experiment}

The present experiment was conducted at Botany Department, University of Allahabad. The drought stress experiment lasted for one growing season. Dry and healthy seeds of Sesbania cannabina variety ND-1 were soaked in distilled water for $14 \mathrm{~h}$. After soaking, the seeds were sown in experimental pots to raise the population. After 15 days, the seedlings were subjected to drought stress for different time durations (viz., 10, 15 and 20 days).

\section{Cytological studies}

On the onset of budding, young floral buds were fixed in carnoy's fixative. After $24 \mathrm{~h}$, the buds were changed in absolute alcohol and were used for cytological analysis. Slides were prepared using the anther squash technique. Slides were scored for meiotic abnormalities and pollen fertility percentages.

\section{Results}

\section{Chromosomal aberrations}

A wide spectrum of chromosomal aberrations was analysed at metaphase, anaphase and telophase stages (Table 1). Control sets illustrated perfectly normal behaviour of chromosomes with 12 bivalents at diakinesis and metaphase-I and 12:12 separations at anaphase-I (Figs. 1 and 2) with no abnormality, whereas in the treated sets substantial increase in abnormality percentage was recorded. Also, varying degrees of chromosomal aberrations (Figs. 3-9) predominantly occurred due to drought stress treatment. Various chromosomal abnormalities such as stickiness, precocious

Table 1. Effect of drought stress on meiosis of Sesbania cannabina.

\begin{tabular}{|c|c|c|c|c|c|c|c|c|c|c|c|c|c|}
\hline \multirow{2}{*}{$\begin{array}{l}\text { Drought } \\
\text { stress }\end{array}$} & \multirow{2}{*}{$\begin{array}{l}\text { No. of } \\
\text { PMCs } \\
\text { observed }\end{array}$} & \multirow{2}{*}{$\begin{array}{l}\text { No. of } \\
\text { abnormal } \\
\text { PMCs }\end{array}$} & \multicolumn{4}{|c|}{$\begin{array}{c}\text { Metaphasic (I and II) } \\
\text { abnormalities (\%) }\end{array}$} & \multicolumn{4}{|c|}{$\begin{array}{l}\text { Anaphasic (I and II) } \\
\text { abnormalities (\%) }\end{array}$} & \multirow{2}{*}{$\begin{array}{c}\begin{array}{c}\text { Telophasic } \\
\text { abnormalities (\%) }\end{array} \\
\mathrm{Br}\end{array}$} & \multirow{2}{*}{ Others $(\%)$} & \multirow{2}{*}{$\begin{array}{c}\text { Total } \\
\text { abnormality (\%) }\end{array}$} \\
\hline & & & $\operatorname{Pr}$ & St & $\mathrm{Sc}$ & $\begin{array}{l}\text { Sec } \\
\text { Ass. }\end{array}$ & $\mathrm{Lg}$ & Un & $\mathrm{Br}$ & Asy & & & \\
\hline Control & 200 & - & - & - & - & - & - & - & - & - & - & & - \\
\hline 10 days & 178 & 10.66 & 0.77 & 0.56 & - & 0.91 & 0.95 & 0.36 & 0.73 & 0.56 & 0.17 & 0.95 & 6.01 \\
\hline 15 days & 187.66 & 14.33 & 0.86 & 0.94 & 0.37 & 1.07 & 0.92 & 0.31 & 0.33 & 1.01 & 0.64 & 1.09 & 7.61 \\
\hline 20 days & 173.33 & 17.33 & 1.91 & 1.11 & 0.34 & 1.54 & 1.57 & 0.57 & 1.33 & 0.75 & - & 0.82 & 9.99 \\
\hline
\end{tabular}

$\mathrm{Pr}=$ precocious movement, $\mathrm{St}=$ stickiness, $\mathrm{Sc}=$ scattering, Sec Ass.=secondary association, Lg=laggards, Un=unorientation, $\mathrm{Br}=$ bridges, $\mathrm{Asy}=$ asynchronus, other abnormalities: tripolarity, bivalents etc. 



Figs. 1-9. 1. Normal metaphase $(n=12), 2$. normal anaphase $(12: 12), 3$. unorientation at metaphase I, 4. laggards at anaphase I, 5. chromatin bridge at anaphase I, 6. multivalents at metaphase I, 7. multiple bridge at anaphase I, 8. precocious movement at metaphase I, 9. scattering at metaphase I.

movement, secondary association, laggards, bridge, etc. were present in high frequency, whereas, scattering, unorientation at anaphase, asynchronous division at anaphase, etc. occurred at lower rates. It was observed that the percentage of metaphasic abnormalities was more frequent than the anaphasic abnormalities. The total abnormality percentage registered at 10 days of stress treatment was $6.01 \%$ while it increased to $9.99 \%$ at 20 days of drought stress treatment. Among all the chromosomal aberrations monitored, precocious movement at metaphase was the most frequent abnormality. Percentage of precocious movement at metaphase was observed to be $1.91 \%$ at 20 days of treatment of drought stress while it was minimum $(0.77 \%)$ at 10 days of stress treatment. Laggards at anaphase, secondary association at metaphase and bridge at anaphase were the next most dominant abnormalities, recorded to be $1.57 \%, 1.54 \%$ and $1.33 \%$, respectively, at 20 days of drought stress treatment. In case of telophasic abnormalities, only bridges were observed and were absent at the highest time duration of stress treatment.

\section{Pollen fertility}

Pollen fertility was analyzed from each treatment set. There was not much decrease in pollen fertility in drought stress treatments (Table 2). Control plants exhibited $95.50 \%$ pollen fertility, 
Table 2. Effect of drought stress on pollen fertility percentages of Sesbania cannabina.

\begin{tabular}{cc}
\hline \hline Drought stress & Pollen fertility percentage \\
\hline Control & 95.50 \\
10 days & 93.40 \\
15 days & 90.81 \\
20 days & 89.33 \\
\hline
\end{tabular}

while it reduced to $89.33 \%$ at the highest days of drought stress treatment.

\section{Discussion}

Drought, salt and cold stresses are associated with changes in the genome, proteome and metabolome (Lerner 1999). Drought stress causes stomata closure and reduced $\mathrm{CO}_{2}$ diffusion into leaves, limiting photosynthesis, and it reduces cell division, enlargement and differentiation (Begg 1980), resulting in a reduction of the leaf area and biomass of the plant (Osório et al. 1998, Rhodenbaugh and Pallardy 1993, Guarnaschelli et al. 2003). Evaluation of chromosomal variations resulting from the application of water stress gives an account of the mechanism of action of these abiotic stresses (Heckenberger et al. 1998, Cheptou et al. 2000, Rizhsky et al. 2002). Microsporogenesis analysis was done to study the chromosomal behaviour at meiosis in order to correlate it with fertility of the species. These stress treatment lead to various kinds of chromosomal damages, which can be observed as anomalies. A dose-based increase in chromosomal abnormalities was evident in the present case as well. Total abnormality percentage was comparatively higher in the case of a 20-day stress treatment. Cytological abnormalities such as precocious movement, laggard, secondary associations, etc. were more frequent at all the treatment doses. This implies that the stress treatment may have brought some alterations in the pattern of organisation of chromosomes. Precocious movement of chromosomes seems to be a manifestation of improper functioning of the spindle. Stebbins (1950) and Darlington (1928) interpreted secondary associations to be a result of modified chromosome arrangements due to duplication, interchanges or stickiness. Jayabalan and Rao (1987) reported stickiness due to disturbances in the cytochemically balanced reactions. Evans (1986) reported stickiness to be a result of partial dissociation of nucleoproteins and changes in the pattern of organization. Unorientation and scattering of chromosomes may either be due to the inhibition of spindle formation or due to the destruction of spindle fibres formed. Higher frequency of chromosomal abnormalities might interfere with the proper tetrad formation which might result in the increase in pollen and ovule sterility and subsequent results such as high reduction in yield. Stress treated plants showed high seed sterility which could be attributed to either pollen or ovule sterility or both at the different stages. Thus, on the basis of the present undertaken study, it can be clearly concluded that drought stress treatment has mutagenic behaviour causing various types of chromosomal aberration.

\section{Acknowledgements}

The author is grateful to Sunn Hemp Research Station, Pratapgarh, U. P., India for providing inbred seeds of Sesbania cannabina Variety ND-1.

\section{References}

Araus, J. L., Slafer, G., Royo, C. and Serret, M. D. 2008. Breeding for yield potential and stress adaptation in cereals. CRC 
Crit, Rev. Plant Sci. 27: 377-412.

Begg, J. E. 1980. Morphological adaptations of leaves to water stress. In: Turner, N. C. and Kramer P. J. (eds.). Adaptation of Plants to Water and High Temperature Stress. John Wiley \& Sons, Inc., New York. pp. 31-42.

Cattivelli, L., Baldi, P., Crosatti, C., Di Fonzo, N., Faccioli, P., Grossi, M., Mastrangelo, A. M., Pecchioni, N. and Stanca, A. M. 2002. Chromosome regions and stress-related sequences involved in resistance to abiotic stress in Triticeae. Plant Mol. Biol. 48: 649-665.

Cheptou, P., Berger, A., Blanchard, A., Collin, C. and Escarre, J. 2000. The effect of drought stress on inbreeding depression in four populations of the Mediterranean outcrossing plant Crepis sancta (Asteraceae). Heredity $\mathbf{8 5}$ : 294-302.

Cruz, R. T., Jordan, W. R. and Drew, M. C. 1992. Structural changes and associated reduction of hydraulic conductance in roots of Sorghum bicolor L. following exposure to water deficit. Plant Physiol. 99: 203-212.

Darlington, C. D. 1928. Studies in Prunus I and II. J. Genet. 19: 215-221.

Eberhart, S. A. and Russell, W. A. 1966. Stability parameters for comparing varieties. Crop Sci. 6: 36-42.

Evans, D. O. 1986. Sesbania research in Hawaii: Summary of a project. Nitrogen Fixing Tree Research Reports 4: 57-58.

Finlay, K. W. and Wilkinson, G. N. 1963. The analysis of adaptation in a plant-breeding programme. Aust. J. Agric. Res. 14: $742-754$.

Fischer, R. A. and Maurer, R. 1978. Drought resistance in spring wheat cultivars. I. Grain yield response. Aust. J. Agric. Res. 29: 897-907.

Guarnaschelli, A. B., Lemcoff, J. H., Prystupa, P. and Basci, S. O. 2003. Responses to drought preconditioning in Eucalyptus globules Labill. provenances. Trees 17: 501-509.

Heckenberger, U., Roggatz, U. and Schurr, U. 1998. Effect of drought stress on the cytological status in Ricinus communis. J. Exp. Bot. 49: 181-189.

Jayabalan, N. and Rao, G. R. 1987. Gamma radiation induced cytological abnormalities in Lycopersicon esculentum Mill. Var. Pusa Ruby. Cytologia 52: 1-4.

Kramer, P. J. and Boyer, J. S. 1995. Water Relations of Plants and Soils. Academic Press, San Diego. pp. 1-495.

Lerner, H. R. (ed.) 1999. Plant Responses to Environmental Stresses. Marcel Dekker, New York.

Osório, J., Osório, M. L., Chaves, M. M. and Pereira, J. S. 1998. Water deficits are more important in delaying growth than in changing patterns of carbon allocation in Eucalyptus globulus. Tree Physiol. 18: 363-373.

Rhodenbaugh, E. J. and Pallardy, S. G. 1993. Water stress, photosynthesis and early growth patterns of cuttings of three Populus clones. Tree Physiol. 13: 213-226.

Rizhsky, L., Liang, H. and Mittler, R. 2002. The combined effect of drought stress and heat shock on gene expression in tobacco. Plant Physiol. 130: 1143-1151.

Stebbins, G. L., Jr. 1950. Variation and Evolution in Plants. Columbia University Press, New York.

Voltas, J., Lopez-Corcoles, H. and Borras, G. 2005. Use of biplot analysis and factorial regression for the investigation of superior genotypes in multi environment trials. Eur. J. Agron. 22: 309-324. 